\title{
Evaluation of 15 local plant species as larvicidal agents against an Indian strain of dengue fever mosquito, Aedes aegypti L. (Diptera: Culicidae)
}

\section{Sarita Kumar*, Naim Wahab, Monika Mishra and Radhika Warikoo}

Mosquito Control Laboratory, Acharya Narendra Dev College, University of Delhi, New Delhi, India

\section{Edited by:}

Rubén Bueno-Marí, University of

Valencia, Spain

Reviewed by:

Scott H. Harrison, North Carolina A\&T

State University, USA

Ronald Yesid Maestre Serrano,

Ministry of Health, Colombia

${ }^{*}$ Correspondence:

Sarita Kumar, Department of Zoology,

Acharya Narendra Dev College,

University of Delhi, Govindpuri,

Kalkaji, New Delhi 110019, India.

e-mail: sarita.sanjay90@gmail.com

\begin{abstract}
The adverse effects of chemical insecticides-based intervention measures for the control of mosquito vectors have received wide public apprehension because of several problems like insecticide resistance, resurgence of pest species, environmental pollution, toxic hazards to humans, and non-target organisms. These problems have necessitated the need to explore and develop alternative strategies using eco-friendly, environmentally safe, biodegradable plant products which are non-toxic to non-target organisms too. In view of this, 15 plant species were collected from local areas in New Delhi, India. Different parts of these plants were separated, dried, mechanically grinded, and sieved to get fine powder. The $200 \mathrm{~g}$ of each part was soaked in $1000 \mathrm{~mL}$ of different solvents separately and the crude extracts, thus formed, were concentrated using a vacuum evaporator at $45^{\circ} \mathrm{C}$ under low pressure. Each extract was screened to explore its potential as a mosquito larvicidal agent against early fourth instars of dengue vector, Aedes aegypti using WHO protocol. The preliminary screening showed that only 10 plants possessed larvicidal potential as they could result in $100 \%$ mortality at $1000 \mathrm{ppm}$. Further evaluation of the potential larvicidal extracts established the hexane leaf extract of Lantana camara to be most effective extract exhibiting a significant $\mathrm{LC}_{50}$ value of $30.71 \mathrm{ppm}$ while the Phyllanthus emblica fruit extract was found to be least effective with an $\mathrm{LC}_{50}$ value of $298.93 \mathrm{ppm}$. The extracts made from different parts of other five plants; Achyranthes aspera, Zingiber officinalis, Ricinus communis, Trachyspermum ammi, and Cassia occidentalis also possessed significant larvicidal potential with $\mathrm{LC}_{50}$ values ranging from 55.0 to $74.67 \mathrm{ppm}$. Other three extracts showed moderate toxicity against $A$. aegypti larvae. Further investigations would be needed to isolate and identify the primary component responsible for the larvicidal efficiency of the effective plants.
\end{abstract}

Keywords: Aedes aegypti, plant parts, crude extracts, larvicidal agent, toxic component

\section{INTRODUCTION}

The importance of mosquitoes as important disease vectors transmitting diseases like malaria, filariasis, Japanese encephalitis, and dengue is well reported (Becker et al., 2003). Their potential to feed on more than one individual, during a single gonotrophic cycle is causing spread of diseases at larger scale (Mackenzie et al., 2004). Aedes aegypti, the primary carrier for viruses that cause dengue fever, dengue hemorrhagic fever, chikungunya, and yellow fever is widespread over large areas of the tropics and subtropics (Service, 1983; Yang et al., 2009). At present, no effective vaccine is available for dengue; therefore, the only way of reducing the incidence of this disease is by mosquito control, which is frequently dependent on applications of conventional synthetic insecticides (Malavige et al., 2004). According to WHO (2009) about two-fifth of the world's population is now at risk of dengue and the only way to prevent dengue virus transmission is to combat the diseasecarrying mosquitoes. In 2010, a total of 28,292 cases and 110 deaths were reported in India because of dengue (NVBDCP, 2011).

The approach to combat these diseases largely relies on interruption of the disease transmission cycle by either targeting the mosquito larvae at breeding sites through spraying of stagnant water or by killing/repelling the adult mosquitoes using insecticides (Corbel et al., 2004; Joseph et al., 2004). In the past, synthetic organic chemical insecticides-based intervention measures for the control of insect pests and disease vectors have resulted in development of insecticide resistance in some medically important vectors of malaria, filariasis, and dengue fever (WHO, 1992; Singh et al., 2002; Kumar and Pillai, 2010, 2011). Insecticide resistance is increasingly becoming a problem for many vector control programs. Resistance may develop due to changes in the mosquitoes' enzyme systems, resulting in more rapid detoxification or sequestration of the insecticide, or due to mutations in the target site preventing the insecticide-target interaction (Hemingway et al., 2004). The frequent use of chemical insecticides to manage insect pests leads to a destabilization of the ecosystem and enhanced resistance to insecticides in pests (Kranthi et al., 2001). To alleviate these problems, major emphasis has been on the use of natural plant based products as larvicides which can be a safe alternate to synthetic insecticides (Zhu et al., 2008). Biologically active plant extracts have been well documented for evolving an ecologically 
sound and environmentally accepted mosquito control program. These provide an alternative to synthetic pesticides because of their generally low environmental pollution, low toxicity to humans, and other advantages. In addition, increasing documentation of negative environmental and health impact of synthetic insecticides and increasingly stringent environmental regulation of pesticides (Isman, 2000) have resulted in renewed interest in the development and use of botanical insect management products for controlling mosquitoes and other insect pests.

A number of such plant products have been used for insect control since time immemorial. Many researchers have reported the effectiveness of plant extracts or essential oils as efficient mosquito larvicides and repellents without posing hazards of toxicity to humans (Amer and Mehlhorn, 2006a,b; Rahuman et al., 2009a,b). More than 2000 plants species have been known to produce chemical factors and metabolites of value in pest control programs (Ahmed et al., 1984), and among these plants, products of some 344 species have been reported to have a variety of activities against mosquitoes (Sukumar et al., 1991). However, very few plant products have been developed for controlling mosquitoes. Phytochemicals, extracted from the whole plant or specific part of the plant using different solvents may also act against mosquitoes as growth regulators, repellents, and ovipositional deterrent (Amer and Mehlhorn, 2006b; Rajkumar and Jebanesan, 2007).

In view of this, 15 plants were collected from local areas in New Delhi, India and its surrounding regions. The different parts of these plants were evaluated in the laboratory in terms of their larvicidal potential against dengue vector, $A$. aegypti. The assessment of plants for mosquito larval toxicity may help in the formulation of effective strategies for reduction of its population.

\section{MATERIALS AND METHODS REARING OF MOSQUITOES}

The present investigations employ the dengue fever mosquito, $A$. aegypti originated from fields of Delhi and surrounding areas. The colony was maintained in an insectary at $28 \pm 1^{\circ} \mathrm{C}, 80 \pm 5 \% \mathrm{RH}$, and 14L: 10D photoperiod (Kumar et al., 2010). Adults were supplied with freshly soaked deseeded raisins. Periodic blood meals were provided to female mosquitoes for egg maturation by keeping restrained albino rats in the cages. The eggs were collected in a bowl lined with Whatman filter paper and were allowed to hatch in trays filled with de-chlorinated water. Larvae were fed upon a mixture of yeast powder and grinded dog biscuits. The pupae formed were collected and transferred to the cloth cages for adult emergence.

\section{COLLECTION OF PLANT MATERIAL}

A total of 15 plant species were selected on the basis of their easy availability, uncomplicated cultivation, and possibility of commercialization. It was taken care that these species were not threatened, endangered, and endemic species; and few of them carry some medical importance. The species were gathered from the surrounding areas and brought to the laboratory in polythene bags. Each plant species belonged to a different family. Different parts, with well known fact of non-toxicity to human beings and traditional use in domestic or industrial consumption, were separated from each species and were thoroughly washed with tap water in order to clean dust or any particles stuck to them. The plant parts were observed carefully to find any kind of disease or infection and if found any, those parts were separated and not used for the experiment. The selected parts were kept for drying under shade at room temperature $\left(27 \pm 2^{\circ} \mathrm{C}\right)$ for about 20 days till they dried completely. The 15 plant species and the parts used in the present study are tabulated in Table 1.

\section{PREPARATION OF EXTRACTS}

The dried parts were mechanically grinded and sieved to get fine powder. The $200 \mathrm{~g}$ of each dried and powdered part was extracted with $1000 \mathrm{~mL}$ of hexane using soxhlet extraction apparatus for $24 \mathrm{~h}$ at a temperature not exceeding the boiling point of the solvent.

Table 1 | Details of the plant species screened and the larvicidal activity of $1000 \mathrm{ppm}$ crude hexane extracts of selected parts of these plant species against dengue vector Aedes aegypt $i$.

\begin{tabular}{|c|c|c|c|c|}
\hline Name of the plant species & Local name & Family & Part used & $\%$ Mortality after $24 \mathrm{~h}$ \\
\hline Abutilon indicum & Indian mellow & Malvaceae & Stem & 100 \\
\hline Achyranthes aspera & Prickly chaff flower & Amaranthaceae & Stem & 100 \\
\hline Phyllanthus emblica & Amla, Indian gooseberry & Phyllanthaceae & Fruit & 100 \\
\hline Cassia occidentalis & Chakunda, coffee senna & Caesalpiniaceae & Leaves & 100 \\
\hline Allium sativum & Garlic & Amaryllidaceae & stem & 100 \\
\hline Zingiber officinale & Ginger & Zingiberaceae & Stem & 100 \\
\hline Momordica charantia & Karela, bitter gourd & Cucurbitaceae & Fruit & 100 \\
\hline Lantana camara & Spanish flag, west Indian lantana & Verbenaceae & Leaves & 100 \\
\hline Ricinus communis & Castor oil plant & Euphorbiaceae & Leaves & 100 \\
\hline Trachyspermum ammi & Ajwain, bishop's weed & Apiaceae & Fruits & 100 \\
\hline Putranjiva roxburghii & Putranjiva & Putranjivaceae & Leaves & 0 \\
\hline Chrysanthemum indicum & Mums, guldaudi & Asteraceae & Leaves & 25 \\
\hline Myristica fragrans & Jaiphal, nutmeg & Myristicaceae & Fruits & 10 \\
\hline Bauhinia tomentosa & Kachnar & Fabaceae & Leaves & 0 \\
\hline Melaleuca bracteata & Golden bottle brush, mock olive & Myrtaceae & Leaves & 15 \\
\hline
\end{tabular}


The extracts, thus obtained, were concentrated using a vacuum evaporator at $45^{\circ} \mathrm{C}$ under low pressure. After complete evaporation of the solvent the concentrated extract was collected and stored in a refrigerator at $4^{\circ} \mathrm{C}$ as the stock solution of $1000 \mathrm{ppm}$ for further use.

\section{SCREENING OF EXTRACTS FOR THEIR LARVICIDAL PROPERTIES AGAINST A. AEGYPTI}

The bioassays were carried out in two phases. The required concentrations of each extract were prepared using ethanol as a solvent. In the first phase, the extracts were tested against early fourth instar larvae of $A$. aegypti to estimate their toxicity. The early fourth instars of mosquitoes were taken, in batches of 20, in plastic bowls containing $99 \mathrm{~mL}$ of distilled water and transferred to glass jar containing $100 \mathrm{~mL}$ of distilled water and $1 \mathrm{~mL}$ of 1000 ppm of extract. Four replicates were carried out simultaneously for each extract making a total of 80 larvae for each test. Controls were exposed to the solvent, i.e., ethanol alone. During the treatment period, the larvae were not provided with any food. The dead and moribund larvae were recorded after $24 \mathrm{~h}$ as larval mortality.

The mortality of larvae was determined by observing the movement of the larvae after $24 \mathrm{~h}$ of treatment. The larvae were touched gently with the help of a glass rod. The larvae were considered dead if they showed no sign of movements. The larvae were considered moribund if they moved a little but did not show any kind of swimming movement. The moribund larvae were considered dead as these larvae could never revive.

The extracts that failed to give $100 \%$ mortality after treatment for $24 \mathrm{~h}$ were no longer used, whereas the extracts that provided $100 \%$ mortality after treatment for less than $24 \mathrm{~h}$ were selected and used for the next stage of the study.

EVALUATION OF SELECTED EXTRACTS AGAINST LARVAE OF A. AEGYPTI Following the results of the first stage, bioassays were conducted to calculate the $\mathrm{LC}_{50}$ values of selected extracts against the early fourth instar larvae of A. aegypti. The larvicidal bioassay was performed at $28 \pm 1^{\circ} \mathrm{C}$ on $A$. aegypti larvae in accordance with the procedure described by WHO with slight modifications (WHO Report, 2005). The graded series of each of the selected extracts was prepared using ethanol as the solvent. The tests were carried out with each dilution of each extract as described earlier. Four replicates were carried out simultaneously for each dilution making a total of 80 larvae for each concentration of each extract. Controls were exposed to the solvent, i.e., ethanol alone.

\section{DATA ANALYSIS}

The tests with more than $20 \%$ mortality in controls and pupae formed were discarded and repeated again. If the control mortality ranged between 5 and 20\%, it was corrected using Abbott's formula (Abbott, 1925).

$$
\begin{aligned}
& \text { Corrected Mortality } \\
& \qquad=\frac{\% \text { Test Mortality }-\% \text { Control Mortality }}{100-\% \text { Control Mortality }} \times 100
\end{aligned}
$$

The data were subjected to regression analysis using computerized SPSS 11.5 Program. The $\mathrm{LC}_{50}$ and $\mathrm{LC}_{90}$ values with 95\% fiducial limits and chi-square were calculated in each bioassay to assess the significance and measure difference between the test samples.

\section{RESULTS \\ SCREENING OF EXTRACTS FOR THEIR LARVICIDAL PROPERTIES AGAINST A. AEGYPTI}

In the first phase of study, $1000 \mathrm{ppm}$ extracts made from different parts of 15 plant species, collected from Delhi and surrounding areas were tested against early fourth instars of $A$. aegypti. The per cent mortality observed after $24 \mathrm{~h}$ revealed that out of 15 species, only 10 species could result in $100 \%$ mortality. The details of the species collected and mortality data is presented in Table 1. Other plant extracts resulted in only $0-25 \%$ mortality and thus these species were rejected for further bioassays.

\section{EVALUATION OF SELECTED EXTRACTS AGAINST LARVAE OF A. AEGYPTI}

The larvicidal efficiencies of the selected extracts were evaluated against early fourth instars of $A$. aegypti. The mortality data is presented in Table 2 . Bioassays performed with 10 extracts revealed their potency to kill larvae of $A$. aegypti. The treatment resulted in complete mortality with no pupal or adult emergence. The control or untreated group did not exhibit any mortality within $24 \mathrm{~h}$.

Our investigations revealed that hexane extract made from the leaves of Lantana camara was the most effective extract exhibiting a significant $\mathrm{LC}_{50}$ value of $30.71 \mathrm{ppm}$. On the other hand the extract made from amla fruit was least effective with an $\mathrm{LC}_{50}$ value of $298.93 \mathrm{ppm}$ thus exhibiting 9.4-fold fewer efficacy than Lantana leaves (Table 2; Figure 1). It was also observed that the extracts made from Achyranthes aspera (stem), Zingiber officinale (stem), Ricinus communis (leaves), Trachyspermum ammi (fruits), and Cassia occidentalis (leaves), though 1.8-2.4 times less effective than Lantana leaves possessed significant larvicidal potential with quite low $\mathrm{LC}_{50}$ values ranging from 55.0 to $74.67 \mathrm{ppm}$ (Figure 1).

Other extracts showed only moderate toxicity against $A$. aegypti larvae. The stem extract of Abutilon was found to be 5.98-fold less effective than extract of L. camara leaves but 1.6-fold more effective than amla extracts. Likewise, the stem extract of garlic showed 7.1-less efficacy than Lantana leaf extract and only 1.4-fold more effective than amla extract; while karela fruit extract exhibited 8.5fold less toxicity than extract of Lantana leaves but only 1.1-fold more effective than that of amla fruits (Table 2; Figure 1).

The study revealed that the $\mathrm{LC}_{50}$ values obtained from the extracts made from Lantana leaves and amla fruit were significantly different from that obtained from other extracts. The extracts made from Achyranthes (stem), Zingiber (stem), Ricinus (leaves), Trachyspermum (fruits), and Cassia (leaves) resulted in mortalities that were not significantly different from each other but were significantly different from those caused by other extracts. Similarly, the extracts from Abutilon stem, garlic stem, and karela fruit though significantly different from other extracts did not differ significantly from each other.

\section{DISCUSSION}

The control of mosquito-borne diseases can be achieved either by killing, preventing mosquitoes to bite human beings (by using repellents) or by causing larval mortality in a large scale at the 
Table 2 | Larvicidal bioassay of crude hexane extracts of selected parts of 15 plant species against early fourth instars of Aedes aegypti.

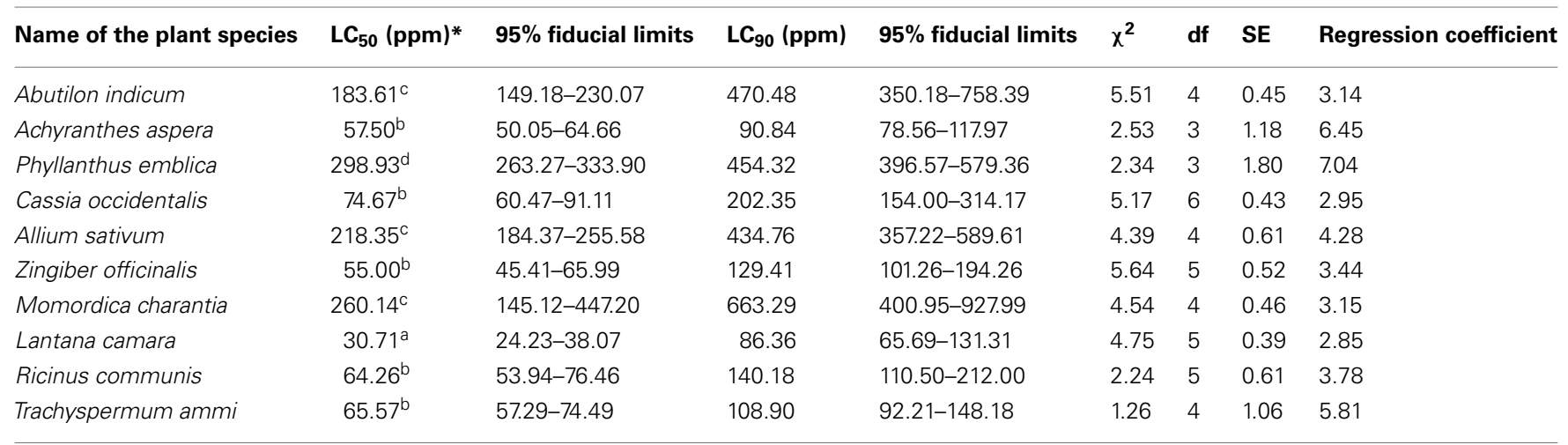

${ }^{*}$ Figures in each column followed by the same letter are not significantly different at $p=0.05$ (Students' $t$-test).

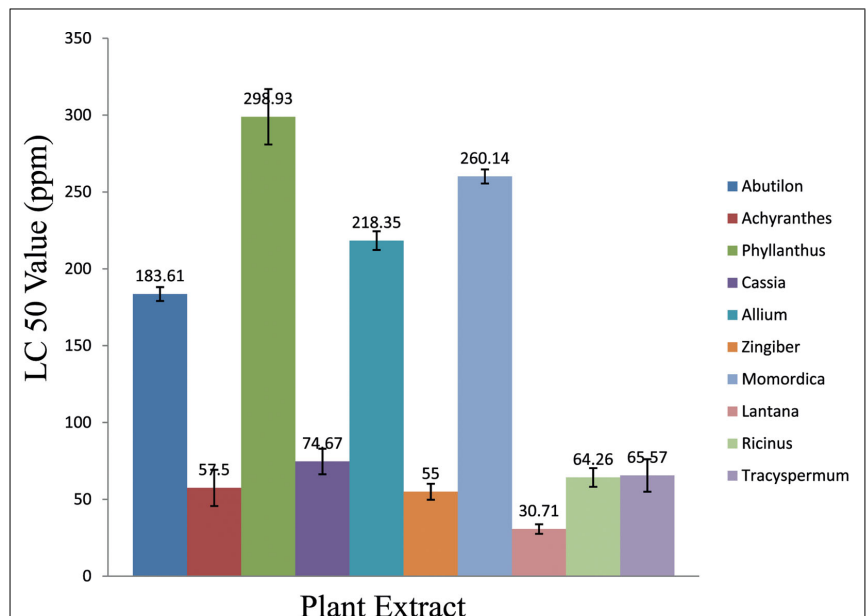

FIGURE 1 | Comparative larvicidal activity of different parts of 10 selected plants against $A$. aegypti.

breeding centers of the vectors in the environment. However, the extensive use of synthetic organic insecticides during the last five decades has resulted in environmental hazards and the development of physiological resistance in the major vector species. This has necessitated the need for search and development of environmentally safe, bio-degradable, low cost, and indigenous methods for vector control, which can be used with minimum care by individual and communities in specific situations (Mittal and Subbarao, 2003).

A number of researches in the field of vector control have revealed the efficacy of different phytochemicals obtained from various plants against different species of mosquitoes. Sukumar et al. (1991) made an extensive review of botanical derivatives tested for mosquito control. A large number of plant extracts have been reported to possess mosquitocidal or repellent activities against mosquito vectors, but very few plant products have shown practical utility for mosquito control. The plant products can be obtained either from the whole plant or from a specific part by extraction with different types of solvents such as aqueous, methanol, chloroform, hexane, ethanol, petroleum ether, etc.
Plants are rich sources of complex mixtures of bioactive compounds that can be used to develop environmentally safe vector and pest-managing agents. It could also be conceived from the review that some phytochemicals act as general toxicants both against adult as well as against larval stages of mosquitoes. The preliminary screening is a good means of evaluation of the potential mosquitocidal activity of plants popularly used for this purpose.

Present study investigates the larvicidal activity of the crude hexane extracts prepared from different parts of 15 local plant species gathered from New Delhi, India and surrounding regions. Our investigations showed that at $1000 \mathrm{ppm}$ only 10 species showed larvicidal activity and thus they were evaluated further for their larvicidal potential. It was revealed that hexane extracts prepared from selected 10 species possess appreciable larvicidal potential against A. aegypti. The hexane leaf extract of L. camara proved to be most effective extract exhibiting a significant $\mathrm{LC}_{50}$ value of $30.71 \mathrm{ppm}$ while the Phyllanthus emblica fruit extract was found to be least effective with an $\mathrm{LC}_{50}$ value of $298.93 \mathrm{ppm}$. The extracts made from different parts of $A$. aspera, $Z$. officinalis, $R$. communis, T. ammi, and C. occidentalis possessed significant larvicidal potential with $\mathrm{LC}_{50}$ values ranging from 55.0 to $74.67 \mathrm{ppm}$. Other extracts showed moderate toxicity against $A$. aegypti larvae.

Our results are comparable with the studies reported by different scientists. Kumar and Maneemegalai (2008) reported that at $1 \mathrm{mg} / \mathrm{mL}$ the ethanol extracts of the leaves of L. camara caused $84 \%$ larval mortality while the methanol extracts showed 48\% mortality in the fourth instar larvae of A. aegypti. The ethanol extracts of $C$. occidentalis prepared from its leaves showed larvicidal activity against the malarial vector Anopheles stephensi at a dose equivalent to $\mathrm{LC}_{50}$ of $70.56 \%$ for IV instar larvae (Dhandapani and Kadarkarai, 2011). Ethanolic extract of Allium sativum bulbs showed significant insecticidal activity against larvae of Aedes albopictus exhibiting $\mathrm{LC}_{50}$ value of $4.48 \mathrm{~g} / \mathrm{L}$ (Tedeschi et al., 2011). The toxicity of crude extract of $R$. communis foliage against fourth instar larvae of Anopheles arabiensis and Culex quinquefasciatus was reported by Elimam et al. (2009). They recorded LC 50 values as $403.65,445.66$, and $498.88 \mathrm{ppm}$ against second, third, and fourth instar larvae of $A$. arabiensis and 1091.44, 1364.58, and 1445.44 ppm against second, third, and fourth instar larvae of $C$. quinquefasciatus, respectively. 
Kamalakannan et al. (2011) reported that methanol extract of the leaves of $A$. aspera caused $50 \%$ mortality of $A$. aegypti larvae at $409 \mathrm{ppm}$. Arivoli and Tennyson (2011) found that the hexane extract of Abutilon indicum leaves caused $100 \%$ mortality at $1000 \mathrm{ppm}$ with $\mathrm{LC}_{50}$ value of $261.31 \mathrm{ppm}$ against the larvae of A. aegypti at $24 \mathrm{~h}$. Our results are in agreement with that of Uthayarasa et al. (2010) who reported an $\mathrm{LC}_{50}$ value of $202.92 \mathrm{ppm}$ with amla fruit hexane extract against third instars of A. aegypti. They also reported that crude extract of amla fruits obtained with dichloromethane proved to be more efficient with $\mathrm{LC}_{50}$ value of $166.64 \mathrm{ppm}$. Singh et al. (2006) carried out investigations with crude aqueous and hexane extracts of Momordica charantia against larvae of A. stephensi, C. quinquefasciatus, and A. aegypti and revealed the $\mathrm{LC}_{50}$ values of $0.50,1.29$, and $1.45 \%$, respectively with aqueous extracts and $66.05,96.11$, and $122.45 \mathrm{ppm}$, respectively with hexane extracts.

The botanical extracts from the plant leaves, roots, seeds, flowers, and bark in their crude form have been used as conventional insecticides for centuries. In fact, many researchers have reported the effectiveness of plant extracts against mosquito larvae (Rasheed et al., 2005; Amer and Mehlhorn, 2006a). Warikoo et al. (2012) showed that $24 \mathrm{~h}$ exposure to early fourth instars of $A$. aegypti with hexane extract of the leaves of Citrus sinensis resulted in $50 \%$ mortality at $446.84 \mathrm{ppm}$. Amusan et al. (2005) revealed the efficacy of the ethanolic extract of the orange peels against the larvae of the yellow fever mosquito, A. aegypti. Kumar et al. (2011) found that the peel of C. limetta extracted in hexane possessed

\section{REFERENCES}

Abbott, W. B. (1925). A method for computing the effectiveness of an insecticide. J. Econ. Entomol. 18, 265-267.

Ahmed, S., Graivge, M., Hylin, J. W., Mitchell, W. C., and Listinger, J. A. (1984). "Some promising plant species for use as pest control agents under traditional farming system," in Proceedings of the 2nd International Neem Conference, eds $\mathrm{H}$. Schmutterer and K. R. S. Ascher (Eschborn), 565-580.

Amer, A., and Mehlhorn, H. (2006a). Larvicidal effects of various essential oils against Aedes, Anopheles, and Culex larvae (Diptera, Culicidae). Parasitol. Res. 99, 466-472.

Amer, A., and Mehlhorn, H. (2006b). Repellency effect of forty-one essential oils against Aedes, Anopheles and Culex mosquitoes. Parasitol. Res. 99, 478-490.

Amusan, A. A., Idowu, A. B., and Arowolo, F. S. (2005). Comparative toxicity of bush tea leaves (Hyptis suaveolens) and orange peel (Citrus sinensis) oil extracts on the larvae of the yellow fever mosquito Aedes aegypti. Tanzan Health Res. Bull. 7, 174-178.

Arivoli, S., and Tennyson, S. (2011). Larvicidal and adult emergence inhibition activity of Abutilon significant larvicidal potential against $A$. stephensi and A. aegypti exhibiting $\mathrm{LC}_{50}$ values of 132.45 and $96.15 \mathrm{ppm}$, respectively.

Our investigations demonstrated the larvicidal potential of various plants extracts of against $A$. aegypti. As the plants are distributed throughout the country and available most of the time, the larvicidal properties of these plant species can be well utilized while planning alternate vector control strategies, based on integrated vector control measures through community-based approaches. The plants are easily available to the local people and multiple medicinal properties, it may be easily acceptable to them, since during application it would neither cause any toxic effect nor any additional economic burden. However, the mechanism causing the larvicidal effect is still unknown and needs to be studied further. Variety of types and levels of active constituents in each extract may be responsible for the variability in their potential against $A$. aegypti. This knowledge may help in designing and implementing an effective strategy from a resistance-management perspective against $A$. aegypti. Further investigations are needed to identify the active ingredient present in the each extract and elucidate their efficacy against $A$. aegypti.

\section{ACKNOWLEDGMENTS}

The authors are thankful to University Grants Commission, New Delhi for providing financial assistance to the project. The authors extend thanks to Dr. Savithri Singh, Principal, Acharya Narendra Dev College for providing the laboratory and culture facilities to conduct the experimental work.

Isman, M. B. (2000). Plant essential oils for pest and disease management. Crop Prot. 19, 603-608.

Joseph, C. C., Ndoile, M. M., Malima, R. C., and Nkuniya, M. H. M. (2004). Larvicidal and mosquitocidal extracts, a coumarin, isoflavonoids and pterocarpans from Neorautanenia mitis. Trans. R. Soc. Trop. Med. Hyg. 98, 451-455.

Kamalakannan, S., Murugan, K., and Barnard, D. R. (2011). Toxicity of Acalypha indica (Euphorbiaceae) and Achyranthes aspera (Amaranthaceae) leaf extracts to Aedes aegypti (Diptera: Culicidae). J. Asia Pac. Entomol. 14, 41-45.

Kranthi, K. R., Jadhav, D., Wanjari, R., and Russell, D. (2001). Pyrethroid resistance and mechanisms of resistance in field strains of Helicoverpa armigera (Lepidoptera: Noctuidae). J. Econ. Entomol. 94, 253-263.

Kumar, M. S., and Maneemegalai, S. (2008). Evaluation of larvicidal effect of Lantana camara Linn against mosquito species Aedes aegypti and Culex quinquefasciatus. Adv. Biol. Res. 2, 39-43.

Kumar, S., and Pillai, M. K. K. (2010). Reproductive disadvantage in an Indian strain of malarial vector, Anopheles stephensi Liston on selections with deltamethrin/synergized deltamethrin. Acta Entomol. Sinica 53, 1111-1118.

Kumar, S., and Pillai, M. K. K. (2011). Correlation between the reproductive potential and the pyrethroid resistance in an Indian strain of filarial vector, Culex quinquefasciatus Say (Diptera: Culicidae). Bull. Entomol. Res. 101, 25-31.

Kumar, S., Warikoo, R., Mishra, M., Seth, A., and Wahab, N. (2011). Larvicidal efficacy of the Citrus limetta peel extracts against Indian strains of Anopheles stephensi Liston and Aedes aegypti L. Parasitol. Res. doi:10.1007/s00436-011-2814-2815

Kumar, S., Warikoo, R., and Wahab, N. (2010). Larvicidal potential of ethanolic extracts of dried fruits of three species of peppercorns against different instars of an Indian strain of dengue fever mosquito, Aedes aegypti L. (Diptera: Culicidae). Parasitol. Res. 107, 901-907.

Mackenzie, J. S., Gubler, D. J., and Peterson, L. R. (2004). Emerging flaviviruses: the spread and resurgence of Japanese encephalitis, West Nile and dengue viruses. Nat. Med. 10, S98-S109

Malavige, G. N., Fernando, S., Fernando, D. J., and Seneviratne, S. L. (2004). Dengue viral infections. Postgrad. Med. J. 80, 588-601. 
Mittal, P. K., and Subbarao, S. K. (2003). Prospects of using herbal products in the control of mosquito vectors. Icmr Bull. 33, 1-10.

National Vector Borne Disease Control Programme (NVBDCP). (2011). Dengue Cases and Deaths in the Country Since 2007. Available at: http://nvbdcp.gov.in/den-cd.html [accessed November 23, 2011].

Rahuman, A. A., Bagavan, A., Kamaraj, C., Vadivelu, M., Zahir, A. A., Elango, G., and Pandiyan, G. (2009a). Evaluation of indigenous plant extracts against larvae of Culex quinquefasciatus Say (Diptera: Culicidae). Parasitol. Res. 104, 637-643.

Rahuman, A. A., Bagavan, A., Kamaraj, C., Saravanan, E., Zahir, A. A., and Elango, G. (2009b). Efficacy of larvicidal botanical extracts against Culex quinquefasciatus Say (Diptera: Culicidae). Parasitol. Res. 104, 1365-1372.

Rajkumar, S., and Jebanesan, A. (2007). Repellent activity of selected plant essential oils the malarial fever mosquito Anopheles stephensi. Trop. Biomed. 24, 71-75.

Rasheed, M., Afshan, F., Tariq, R. M., Siddiqui, B. S., Gulzar, T., Mahmood, A., Begum, S., and Khan, B. (2005). Phytochemical studies on the seed extract of Piper nigrum Linn. Nat. Prod. Res. 19, 703-712.

Service, M. W. (1983). "Management of vectors," in Pest and Vectors Management in Tropics, eds A. Youdeowei and M. W. Service (London: Longman, English Language Book Society), 265-280.

Singh, O. P, Raghavendra, K., Nanda, N., Mittal, P. K., and Subbarao, S. K. (2002). Pyrethroid resistance in Anopheles culicifacies in Surat district, Gujarat, west India. Curr. Sci. 82, 547-550.

Singh, R. K., Dhiman, R. C., and Mittal, P. K. (2006). Mosquito larvicidal properties of Momordica charantia Linn (family: Cucurbitaceae). J. Vector Borne Dis. 43, 88-91.

Sukumar, K., Perich, M. J., and Boombar, L. R. (1991). Botanical derivatives in mosquito control: a review. J. Am. Mosq. Control Assoc. 7, 210-237.

Tedeschi, P., Leis, M., Pezzi, M., Civolani, S., Maietti, A., and Brandolini, V. (2011). Insecticidal activity and fungitoxicity of plant extracts and components of horseradish (Armoracia rusticana) and garlic (Allium sativum). J. Environ. Sci. Health B 46, 486-490.

Uthayarasa, K., Surendran, S. N., Pathmanathan, M. K., and Jeyadevan, J. P. (2010). Larvicidal efficacy of crude extracts of Emblica officinalis and Eucalyptus citriodora against Aedes aegypti L. Int. J. Pharm. Biol. Arch. 1, 467-472.

Warikoo, R., Ray, A., Sandhu, J. K., Samal, R., Wahab, N., and Kumar, S. (2012). Larvicidal and irritant activities of hexane leaf extracts of Citrus sinensis against dengue vector Aedes aegypti L. Asian Pac. J. Trop. Biomed. 2, 152-155.

WHO Report. (2005). World Malaria Report. Geneva: WHO/UNICEF.

World Health Organization (WHO). (1992). Vector resistance to insecticides. 15th report of the $\mathrm{WHO}$ expert committee on vector biology and control. World Health Organ. Tech. Rep. Ser. 818, 1-62.

World Health Organization (WHO). (2009). Dengue and Dengue Haemorrhagic Fever. Available at: http://www.who.int/mediacentre/ factsheets/fs117/en/ [Retrieved November 21, 2011].

Yang, T., Liang, L., Guiming, F., Zhong, S., Ding, G., Xu, R., Zhu, G., Shi, N., Fan, F., and Liu, Q. (2009). Epidemiology and vector efficiency during a dengue fever outbreak in Cixi, Zhejiang province, China. J. Vector Ecol. 34, 148-154.

Zhu, J., Zeng, X., O’Neal, M., Schultz, G., Tucker, B., Coats, J., Bartholomay,
L., and Xue, R.-D. (2008). Mosquito larvicidal activity of botanical-based mosquito repellents. J. Am. Mosq. Control Assoc. 24, 161-168.

Conflict of Interest Statement: The authors declare that the research was conducted in the absence of any commercial or financial relationships that could be construed as a potential conflict of interest.

Received: 31 January 2012; accepted: 02 April 2012; published online: 23 April 2012.

Citation: Kumar S, Wahab N, Mishra $M$ and Warikoo $R$ (2012) Evaluation of 15 local plant species as larvicidal agents against an Indian strain of dengue fever mosquito, Aedes aegypti L. (Diptera: Culicidae). Front. Physio. 3:104. doi: 10.3389/fphys.2012.00104

This article was submitted to Frontiers in Systems Biology, a specialty of Frontier in Physiology.

Copyright (C) 2012 Kumar, Wahab, Mishra and Warikoo. This is an openaccess article distributed under the terms of the Creative Commons Attribution Non Commercial License, which permits non-commercial use, distribution, and reproduction in other forums, provided the original authors and source are credited. 